University of Rhode Island

DigitalCommons@URI

Open Access Master's Theses

2005

\title{
Choosing a Leader: Measurement of Adolescent Perceptions of Leadership
}

Catherine Stephan

University of Rhode Island

Follow this and additional works at: https://digitalcommons.uri.edu/theses

\section{Recommended Citation}

Stephan, Catherine, "Choosing a Leader: Measurement of Adolescent Perceptions of Leadership" (2005). Open Access Master's Theses. Paper 1662.

https://digitalcommons.uri.edu/theses/1662

This Thesis is brought to you for free and open access by DigitalCommons@URI. It has been accepted for inclusion in Open Access Master's Theses by an authorized administrator of DigitalCommons@URI. For more information, please contact digitalcommons-group@uri.edu. 
CHOOSING A LEADER:

MEASUREMENT OF ADOLESCENT PERCEPTIONS OF LEADERSHIP

BY

CATHERINE STEPHAN

A THESIS SUBMITTED IN PARTIAL FULLFILLMENT OF

THE REQUIREMENTS FOR THE DEGREE OF

MASTER OF ARTS

IN

PSYCHOLOGY

UNIVERSITY OF RHODE ISLAND

2005 
Abstract

As the world becomes more complex and demanding, effective leadership is a progressively more important resource. Effective leadership skills are a valuable commodity in many areas of life, such as government, business, community and educational systems. Although there are a considerable number of studies pertaining to adult perceptions of leadership (Fiedler, 1967, Gouldner, 1950, Hook, 1955, Klonsky, 1983, Morris \& Hackman, 1969, Suedfeld,\& Rank, 1976, Wood, 1913), there is a limited amount of research available regarding the development of leadership perceptions in adolescents. This is somewhat surprising given several research findings that identify the development of leadership skills in adolescents as an important indicator of positive social adjustment (McCullough, Ashbridge \& Pegg, 1994; Scales, Benson \& Leffert, 2000). Similarly, the literature pertaining to the measurement of adolescent perceptions leadership is sparse. In fact, most measures of leadership for children and adolescents have been found to be psychometrically inadequate (Oakland, Falkenberg \& Oakland, 1996). Presently, there are no published measures of adolescent perceptions of peer leaders. Although there is some literature on adolescents and leadership emerging within the gifted child literature, there are remarkably few studies pertaining to ways that adolescents develop perceptions of effective leadership (Karnes, \& Bean, 2001, Oakland, Falkenburg \& Oakland, 1996).

The goal of this project was to test a newly developed 20-item measure of adolescent perceptions of peer leadership. This scale is based upon the integrated use of Fielder's Contingency theory of leadership and Selman's theory of social 
awareness development. The hypothesized model for understanding adolescent perception of peer leaders suggested that the development of social awareness will impact an adolescent's perception of effective peer leadership. Thus, it was hypothesized that as adolescents develop higher levels of social awareness, decisions regarding the effectiveness of a potential peer leader will be determined by the goodness of fit between individual leader characteristics and the social context. It was hypothesized that there are three main factors that adolescents consider when making decisions about peer leaders: instrumental behaviors, physical attributes and personality characteristics.

In this study, adolescents were asked to rate peers that were perceived to be effective leaders in three separate scenarios (government, athletic, social contexts). Confirmatory factor analysis and principal component analyses were utilized to investigate the hypothesized three factor structure. Results revealed that the factor structure was not well supported by the original 20 item scale. Post hoc analyses guided the revision of the scale and led to an improved overall fit of the measurement model that maintained an acceptable level of fit across all three situations. It was concluded that further research was needed to verify the appropriateness of the post hoc revisions and to provide independent replication of the hypothesized three factor structure. Although additional analyses did not reveal the presence of significant age differences, some gender differences were noted. 


\section{Acknowledgements}

I would like to thank all my committee members, Bryan Blissmer, Margie Rogers, Joe Rossi and Sue Rossi for all their time and support. I would also like to thank all of my friends and family who have provided ongoing emotional encouragement. Returning to school after so many years of working would not have been possible without all their understanding and support. 


\section{Table of Contents}

Abstract.................................................................

Acknowledgment......................................................

Table of Contents................................................ v

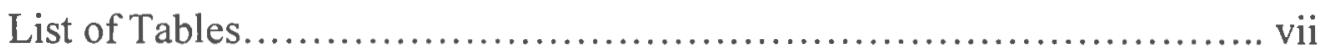

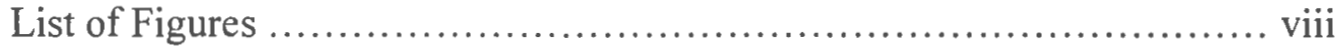

Background and Introduction..................................... 1

Overview of Adult Leadership Literature........................ 1

Fiedler's Contingency Theory of Leadership........................ 3

Predictors of Leadership in Adolescents........................6 6

Social Awareness Development................................... 10

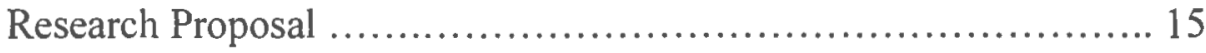

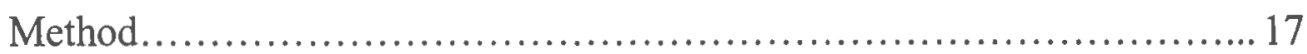

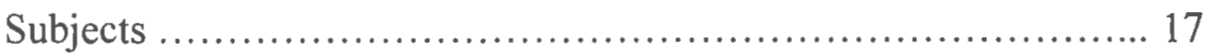

Measures .......................................................... 17

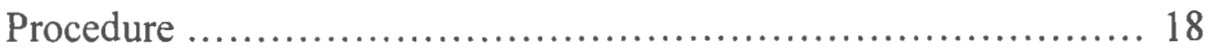

Results....................................................... 20

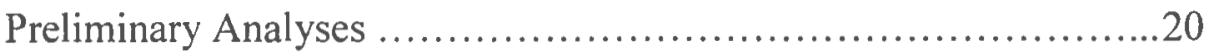

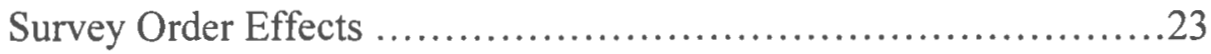

Principal Component Analysis .................................23

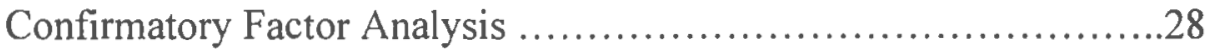

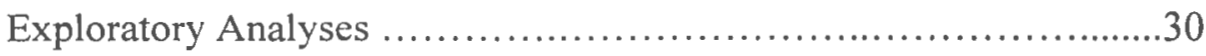


Alternative Model Comparisons

Between Group Analyses ...................................... 38

Discussion........................................................... 40

Measurement Issues ............................................40

Social Awareness Development in Adolescent Perceptions of

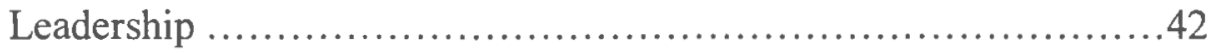

Gender Differences .............................................42

Limitations and Future Research ..................................43

Appendices ..............................................................45

Appendix A............................................... 45

Appendix B................................................... 46

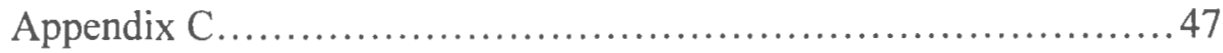

Appendix D................................................ 48

Appendix E....................................................... 49

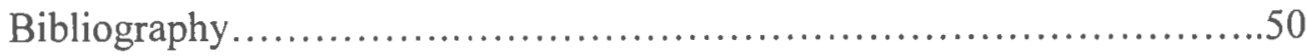


List of Tables

Table Page

Table 1 Fiedler's Contingency Theory Components........................ 6

Table 2 Selman's Social Awareness Development...........................12

Table 3 The Hypothesized Factor Structure ................................15

Table 4 Means and Standard Deviations of Survey Items...................21

Table 5 Government Situation Component Loadings......................25

Table 6 Sport Situation Component Loadings.............................26

Table 7 Social Situation Component Loadings............................27

Table 8 Revised Scale Factor Loading Structure- Government Situation....31

Table 9 Revised Scale Factor Loading Structure- Sport Situation............31

Table 10 Revised Scale Factor Loading Structure- Social Situation..........32

Table 11 Revised Scale Correlations ......................................33

Table 12 Revised Scale Means, Standard Deviations and Coefficient Alphas ...................................................34

Table 13 Comparison of Measurement Models for the Government

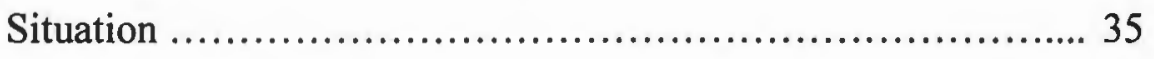

Table 14 Comparison of Measurement Models for the Sport Situation ....36

Table 15 Comparison of Measurement Models for the Social Situation ....36

Table 16 Maximum-likelihood Correlations Between Factors Across

Situations .38 
List of Figures

Figure

Page

Figure 1 - Conceptual Model . 


\section{Background and Introduction}

In today's world, effective leadership is more crucial than ever. Given the sparse amount of literature available regarding youth leadership, more information is needed in the area of adolescent leadership and adolescent perceptions of peer leadership (Schneider, Ehrhart \& Ehrhart, 2002). Increasing the understanding of adolescent perceptions of effective leadership provides valuable insight into the role various mechanisms play in the development of leadership in youth. In order to further explore this area, a review of literature pertaining to adult leadership, Fiedler's Contingency Model of leadership, predictors of adolescent leadership, and social awareness is warranted.

\section{Overview of Adult Leadership Literature}

A majority of available research on adult leadership examines the leadership process in a very limited capacity (Scales, Benson \& Leffert, 2000). Much of the research reviewed focused upon specific personal variables that enhance the probability that leadership behaviors will emerge. These researchers believe leaders are simply born and that they possess "special" characteristics that enable them to rise to the top of most situations (Gouldner, 1950). This "great man" approach to leadership emphasizes internal personal characteristics that are considered to be important for effective leadership. These characteristics facilitate the leader's ability to obtain and hold on to their position as a leader (Gouldner, 1950; Hook, 1955; Wood, 1913).

Conversely, some researchers believe that anyone can be a leader if they are in the right place at the right time (Gouldner, 1950). This is the social determinism 
approach: it stresses the importance of the social climate and the direction of social movements and values. While the "great man" approach views leadership as primarily a function of the individual, social determinists consider leadership primarily a function of the situation (Gouldner, 1950; Simonton, 1979; Suedfeld \& Rank, 1976).

Others believe that the development of leadership entails more than the possession of a certain set of personality qualities or simply being caught up in a particular social situation (Blank, 1986; Fiedler, 1967; Fiedler, 1978; Suedfeld, \& Rank, 1978). For example, Fiedler (1967) presents an integrative approach to leadership. In this view, almost anyone can become a leader under certain circumstances, but some people and personality sets are more regularly identified with leadership. According to Fiedler (1967), the successful development of leadership occurs when an individual is able to successfully combine their personal attributes effectively within a given situation. It appears that an underlying "goodness-of-fit" model may play a role in the development of leadership. Individuals who are able to make successful "goodness-of-fit" decisions regarding leadership are not only aware of the salient personality characteristics of a potential leader and the demands of the situation, but are also conscious of how these two factors are interrelated. The ability to put together these types of environmental cues is often referred to as social awareness. It is hypothesized that individuals with higher levels of social awareness will be more likely to utilize integrative cognitive processes when selecting a leader than individuals with lower levels of social awareness. 
Fiedler's Contingency Theory of Leadership

Fiedler's Contingency theory predicts that the leader's contribution to group functioning depends upon both the personal characteristics of the leader and the favorableness of the situation. A positive interaction between a situation and a person's attributes is needed for successful leadership to occur. Fiedler's Contingency theory has four major components: leader variables, the relationship between the leader and group members, task structure, and position power (Fiedler, 1967). Fiedler's theoretical components are summarized in Table 1.

The first component addresses the personality of the leader. Fiedler (1967) identifies two types of leader personalities: task oriented and interpersonal. The task oriented leader is mainly interested in completing the current task. Their decisions are primarily based upon the demands and nature of the assigned activity. The second type of leader is the more interpersonal leader who emphasizes relational aspects of the group. The interpersonal leader places a greater value on group satisfaction and successful interactions of the group.

The second major component of this theory is the leader-member relationship. This involves the leader's personal relations with the group or organization. Fiedler considered the general group atmosphere to be the most important component in predicting the amount of influence a leader will have in the group. These relations can range anywhere from highly positive to highly negative. This suggests that the leader who attempts to be flexible and sensitive to the group's needs increases their probability that they will be a successful leader within the confines of that particular group. 
A third component is the task structure. Task structure may be defined along three dimensions: goal clarity, solution specificity and decision verifiability. The first dimension, goal clarity, refers to how well the group understands the plan for achieving the goal. The next feature is solution specificity, which refers to the idea that there may be more than one way to solve the problem. The third element of the task structure is decision verifiability. This means that once a decision has been made, the group is comfortable with the final outcome.

The last feature of Fielder's theory is labeled position power; this simply refers to the amount of power and authority that the leadership position inherently carries with it. These four components are important parts of a systems approach to leadership; no one part is independent of all the others.

The interdependence of components permits different combinations of features to be used to predict whether or not an individual will be successful as a leader. Fiedler (1969) contended that there is no such thing as a good leader for all situations. He further concluded that, "A leader who is effective in one situation may or may not be successful in another" (p. 42). Although most research focuses upon the first dimension, personality of the leader, this is considered to be a limited view and not likely to result in an accurate prediction of leadership potential.

An interactional model of leadership considers effective leadership as the relationship between a specific situation and the personal characteristics of the leader. The term "goodness-of-fit" denotes the degree to which the leader's personality and values match the demands and expectations of a specific situation. 
Fiedler (1978) has continued to expand upon the interactional model of leadership by describing leadership as a dynamic system. This implies that effective leadership is an ongoing process that continually affects the way the organization and the leader interact with each other. For example, effective task-oriented leaders are not likely to be as successful in less structured group settings or in groups where the goals are not clearly defined. Likewise, leaders who emphasize interpersonal relationships may not be successful in situations where the group dynamics are very poor and the task is very structured.

Blank (1986) found that many high school leaders rely on personal characteristics (e.g., charisma), however, these personal characteristics were not sufficient for the leaders to maintain their positions independent of the demands of the task. High school leaders believed that the most effective leader is one who is concerned about the group task as well as whether the group members feel positively about each other. This suggested that at the high school level there seems to be recognition of the importance of both personality variables and the compatibility between the leader and the target task.

This conceptual framework has been provided as a guide to facilitate the understanding of the interactions between leaders and the environment. Thus, it is not enough for a leader to just be in the right place at the right time. It is also not enough for a leader to simply possess a particular set of "leadership characteristics" or skills. An effective leader is a person who not only has several positive leadership characteristics but is also perceived as being able to fit into the situation and its demands. 
Table 1

Fiedler's Contingency Theory Components

Components Description

Leader Personal Attributes Task-oriented vs. Interpersonal

Relationship Variables Highly positive vs. highly negative

Task Structure Goal Clarity,

Solution specificity

Decision verifiability

Position Power Inherent level of authority

\section{Predictors of Leadership in Adolescents}

Historically, research has identified many different characteristics that relate to the probability of a person being perceived as a leader (Hook, 1955). Klonsky (1983) stated that individuals who are viewed as athletic and assertive are more likely to be considered effective leaders. A recent study completed with high school students concluded that athletes outscored non-athletic peers on a leadership ability measure (Dobosz \& Beaty, 1999). Some studies have indicated that there are gender differences in how children prioritize leadership variables (Crockett, Losoff, \& Petersen, 1984). These results indicated that boys were more likely to consider achievement-based characteristics, such as athletic achievement, academic achievement and popularity. In contrast, girls identified "trait" variables 
such as personality and physical appearance as more important in determining a peer leader.

Hannah (1979) identified two clusters of behaviors that may characterize a leader. The first cluster was referred to as instrumental behaviors: this includes such features such as having many ideas, being hard working, having organizational abilities and possessing athletic or other special talents. These instrumental traits were considered to be highly useful in the completion of a task goal. A second cluster of characteristics described personality traits such as being friendly, attractive, popular, enthusiastic, sensitive and having a "good" personality. The personality cluster identified traits that were highly effective in improving the satisfaction and interpersonal dynamics within a group. Morris and Hackman (1969) also found that leaders compared to non-leaders emphasized facilitative activities (i.e., proposed solutions, worked well in the group) and tended to de-emphasize detrimental activities or behaviors (e.g., argumentative, critical). Similarly, McCullough et al. (1994) found that adolescent leaders were more likely to have an internal locus of control than non-leader adolescents. Adolescent leaders also were found to have higher career aspirations than their non-leader peers.

Popularity has also been identified as an important trait for leaders. Peery (1979) defined a popular person as having both high social impact and high peer acceptance. Research has found that the impact of an individual's popularity greatly depends upon age of the recipient and their understanding of concepts such as friendship, gender relationships and personality features (Oppenheimer \& 
Thijasen, 1983). Thus, the impact of popularity appears to have a differential impact upon children at various stages of social awareness. As noted in other reviews (Asher \& Hymel, 1981; Hartup, 1983), popularity has been found to be a multi-dimensional construct, which includes gender, race, physical attractiveness, special education status, social knowledge, ability to engage others in an interaction, intelligence and academic achievement. Therefore, it is difficult to gain a clear understanding of the role popularity plays among children and adolescents and its relationship to their perceptions of a successful peer leader. Attractiveness is a characteristic that is often associated with popularity (Asher, Markell \& Hymel, 1981; Hartup, 1983). Zakin (1983) stated that "attractiveness is a powerful attribute which can compensate for deficiencies in other areas" (p. 120). He concluded that attractiveness is more influential in choosing peer preferences than either athletic ability or sociability (Zakin, 1983).

Creativity and flexibility characteristics were also found to be important for leadership acquisition (Fu, Canaday, \& Fu, 1982). Creativity was defined as the ability to generate original and unique ideas. The term flexibility refers to the ability to adjust the leadership role to fit the needs of the group and complete the task. Blank (1986) surveyed high school leaders and found that high school leaders rated a flexible response style as essential for the maintenance of effective leadership.

Several researchers have found that intelligence plays an important role in the development of leaders (Breckenbridge \& Vincent, 1968; Fleming, 1935; Gouldner, 1950; Morris \& Hackman, 1969; Schneider et al, 2002). Breckenbridge 
and Vincent (1968) demonstrated that children who possess above average abilities were more able to sustain a leadership role. Leadership was found to be related to the leader's age, intelligence, school marks and social status. Gouldner (1950) stated that leaders tend to have higher intelligence than the group average. However, Gouldner added that there is an optimal degree of intelligence beyond which intelligence seems to interfere with leadership acquisition (i.e., some highly intelligent individuals lack social skills needed for leadership). Morris and Hackman (1969) also supported this notion and suggested that in some social situations high achievement and intelligence may be a "social liability".

Fleming (1935) found that leadership correlated with the ability to be: lively, amusing, intelligent, athletic, interesting, having a pleasant voice, being a good sport, not being modest and having a wide range of interests. Additionally, Nutting (1923) found that gymnastic team captains were picked for the following reasons: slightly higher intelligence, physical ability, older chronologically and above average popularity status.

Thus, historically, most research on leadership has simply provided a list of characteristics that appear to be correlated with leadership (Morris \& Hackman, 1969). There are benefits to these findings because they identify qualities that appear be most likely associated with leadership potential. However, experience tells us that not all leaders exhibit this wide array of characteristics. The research frequently ignores many other factors that may influence leadership, such as group composition, social climate or the nature of the task. To date, the research fails to identify any single variable as the critical component in successful leadership. 
Davis and Luthans (1984) state that this reductionist tendency in leadership research, in which general leadership categories are identified and singled out because they appear to explain a great deal, does not provide greater insight into the construct of leadership. According to Davis and Lutherans, "leadership is a relational and interactive construct in which one does not judge a manager's leadership capacity by observing that person's behavior in isolation" (p.239). Thus, studying leadership in a one-dimensional manner may not be a very useful technique for the identification of critical components needed for the understanding of adolescent perceptions of peer leadership.

\section{Social Awareness Development}

The use of Fiedler's Contingency theory requires an individual to have a high degree of social awareness. Social awareness may be defined as the ability to identify and interpret social cues. Thus, to select an effective leader, individuals must be aware and consider the interaction between interpersonal and situational variables.

Selman (2003) identified two core social competencies in the development of social awareness. The first core competency is identified as the ability to be aware of one's own point of view. This encompasses the understanding of one's own point of view as well as the ability to express it or to know when to keep it to oneself. The second core competency includes the capacity to keep in mind the point of view of another person, group or society as a whole.

Selman (1976) theorizes that there are five levels of social awareness development in children. The first stage is referred to as the egocentric level; this 
is characterized by the child's basic inability to recognize that others may interpret the same actions and events in a different manner than they do. The second stage is termed the subjective level, this refers to the unilateral or the "one-way" aspect of relationships. Relationships are based on concrete acts and their prosocial effects. It is during the next stage that relationships begin to be viewed as reciprocal. Often these reciprocal attitudes toward each other are limited to pragmatic or instrumental interests. In the fourth stage, the child recognizes that people are multi-dimensional. Ironically, it is during this stage that the child overgeneralizes the most salient traits of a person as the primary feature of the whole person. It is not until the emergence of the final stage that there is a qualitative difference in the way a child views peer relations. In this stage, relationships involve a very interdependent process that includes the consideration of peers as multi-dimensional entities that influence others differently across various contexts.

An increase in social awareness results in the development of core social competencies. The first core competency entails the ability to take another's point of view. This refers to a child's capacity to empathize and understand the social implications that may be faced by others. A second important dimension of this social competency is the movement away from physical attributes and toward psychological attributes. The child moves away from concrete attributional thinking ("I like him because he has a lot of toys") toward a more personality attributional thinking ("I like him because he is nice"). The child places increasing value on other factors, such as personality or intelligence. 
Table 2

Selman's Stages of Social Awareness Development

Developmental Stage

Egocentric level

Preschool (ages 3-5)
Description

Individual does not clearly differentiate the perceptions of others from own perceptions.
Subjective level

Early elementary (ages 6-7)

Reciprocal level

Upper elementary (ages 8- 11)
Individual understands that own personal perspective can be different from others.
Mutual (third person) level

Middle school (ages 12- 14)
Individual begins to understand another's view their of own perception.

Societal (multidimensional) level Individual understands own perspective High School (ages 14 and up) within the context of multiple perspectives.

An integration of Fiedler's Contingency model of leadership and Selman's development of interpersonal awareness suggests that a child's ability to select appropriate peer leaders develops alongside the emergence of social awareness. 
Based upon the theoretical work presented by Fiedler, leadership is a complex combination of leader personality, task demands, situation and interactional characteristics within the group. However, according to Selman (1980), children do not begin to consider the interactional aspects of relationships until they have reached the final stage of social awareness. Selecting a leader using Fiedler's Contingency model requires an individual to have a high level of social awareness. This includes the cognitive ability to integrate and analyze the impact of all relevant factors. Thus, younger children would be expected to rely heavily on concrete and physical factors to choose peer leaders. For example, she (a peer) is the captain of the team because she's the one who owns the football. As children move into the pre-adolescent stage they are more likely to choose leaders based on an over-generalization of highly valued and salient personality characteristics, with little consideration given to the situation or task demands, he (peer) is the student council representative because he is popular and well-liked.

It is not until adolescents reach the last stage of social awareness that more sophisticated methods of selecting peer leaders emerge. At this level, leaders are chosen based upon the integration of personality traits, skill level and situational factors. For example, she (peer) is the class president because she is intelligent, energetic, organized and well-liked. At this level, adolescents focus upon both personality aspects and instrumental factors. Instrumental behaviors are defined as skills or behaviors needed for an individual to successfully complete a particular task. 
The literature revealed that most of the research on leadership has been done at the second stage (characterized by unilateral relationships), by studying characteristics that seem to be found most commonly in leaders. Although this approach provides some important data, it does very little to increase our understanding of how adolescents perceive peer leaders. 


\section{Research Proposal}

This project was designed to investigate the psychometric properties of a theory-based measure of leadership in adolescents. This instrument was developed based upon the available research on adolescent leadership. Data utilized in this study was collected by the primary investigator as part of a previous study. The data collected was analyzed to address the following hypotheses:

1. The measurement scale conceptualized three primary dimensions that adolescents consider when making judgments about leadership among peers (i.e., instrumental, physical, and personality). This study sought to confirm a three factor structure within the obtained sample. The three factors were expected to be correlated.

Table 3

The Hypothesized Factor Structure:

\begin{tabular}{|c|c|c|}
\hline Instrumental & Physical & Personality \\
\hline 1. Able to solve problems & $\begin{array}{l}\text { 4. Involved in many } \\
\text { activities }\end{array}$ & 2. Cooperative \\
\hline 9. Well organized & 6. Popular & $\begin{array}{l}\text { 3. Sensitive to } \\
\text { other's feelings }\end{array}$ \\
\hline 12. Creative & 7. A good athlete & 5. A fun person \\
\hline 14. Intelligent & 11. Good looking & 8. Friendly \\
\hline 16. Hard worker & 15. An older student & 10. Honest \\
\hline \multirow[t]{2}{*}{ 18. Able to take control } & 17. Talkative & 13. Likeable \\
\hline & 20. Well dressed & 19. Enthusiastic \\
\hline
\end{tabular}


2. Based upon Selman's stages of social development, as adolescents become more socially aware, they will rely more on interactional properties to make leadership choices. It was hypothesized that there would be significant differences between the peer leader ratings completed by older (high school) students and younger (middle school) students. Thus, two additional predictions were proposed:

(a) Younger pre-adolescents will show a greater tendency to overgeneralize one particular aspect of an individual in their selection of peer leaders and relied more heavily on concrete (physical attributes) characteristics of the nominated peers. Thus, middle school students would have higher scores on items reflecting physical attributes of a peer leader than high school students.

(b) Older adolescent (high school students) leader choices would reflect the recognition of the need to match leader traits with the demands of the situation. It was expected that the older adolescents would be more able to recognize the interactional properties of leadership and rate peer leaders in terms of a goodnessof-fit model. High school students would be expected to have higher scores on items that assess instrumental aspects of a peer leader than middle school students. 


\section{Method}

\section{Subjects}

The subjects in this study were both male and female students in the seventh and twelfth grade of a southern Rhode Island public school system. This school region encompasses several small, rural towns and was at the time of the survey administration, primarily a White, working class community. The total sample size was 255 students [176 seventh graders (69\%) and 79 twelfth graders (31\%)]. The seventh grade sample consisted of 72 males (41\%) and 104 females (59\%) between the ages of 12 years, 3 months to 14 years, 6 months. The twelfth grade sample comprised of 36 males (46\%) and 43 females (54\%), ranging in age from 17 years, 2 months to 19 years of age. The distribution of gender did not differ across grade $\left(\chi^{2}(1,255)=0.485, \mathrm{p}=.486\right)$.

\section{Measures}

This investigation was conducted with the use of a newly created leadership instrument developed by the primary research investigator and supported by the available research on leadership. Item selection was reviewed by a small group of three school psychology graduate students to assess relevance, age-appropriateness and readability of all scale items. The final survey consisted of a list of 20 characteristics on which the subjects rated a perceived peer leader on a 5-point Likert scale. Likert scale choices ranged from "very true of this person" to "not true of this person". The 20 items on the survey were categorized into three attributional dimensions: instrumental, physical, and personality. The instrumental scale included six items emphasizing peer traits useful in task completion (i.e., 
well organized, intelligent). The physical scale consisted of seven items stressing highly salient and concrete features of an individual (i.e., good looking, popular). Finally, the personality scale was comprised of seven items focusing on interpersonal skills of the potential leader (i.e., friendly, likeable). These three dimensions were incorporated into three survey situations: student government, athletic team, and social committee.

\section{Procedure}

A short presentation (approximately 10 minutes) was given to students in the seventh and twelfth grade during their social studies classes. Each presentation included information regarding the nature of the surveys and the importance of parental permission for the participation in the study. When parent consent forms were sent back, students' names were then placed on a list of students eligible for continued participation.

The administration of all three surveys was completed by the primary investigator approximately 3-5 weeks after the initial presentation. This study primarily consisted of the administration of three separate survey situations to students in the seventh and twelfth grade. Students who were not interested in participating or did not return parent permission forms were given 10 minutes of free time. In an attempt to control for any order effects, survey order was counterbalanced.

Students were given standardized directions prior to the administration of any survey (see Appendix B). Each survey required the students to think of a peer that they perceived as an effective leader in each of the three situations: a student 
government position, an athletic team position, and a social committee position. The students were asked to rate the peer chosen for each situation on the 20 listed characteristics. Students filled out one survey for each of the three leadership positions during a single administration session. Total administration time for the completion of the three survey forms was approximately 10 to 15 minutes.

To ensure student's privacy, students were instructed not to write their name or any other identifying information on survey forms. Students were asked to record their gender and the month and year of their birth (i.e., this was included solely to get an estimated age range of participating students). 


\section{Results}

Preliminary Analyses

Prior to any statistical analyses, the entire data set was checked for accuracy and missing data points. Data from the entire sample was retained for analyses. The results of descriptive statistic computations revealed that the item means tended to fall within the higher end of possible scores with the highest item mean of 4.62 on item number 5 on the social situation scale ("fun person"). The lowest item mean was 2.21 found on the sport situation scale for item number 15 ("an older student"). The item means and standard deviations are listed in Table 4. 
Table 4

Means and Standard Deviations for Scale Items

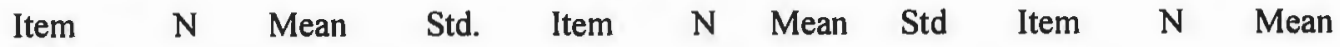

Std.

Dev.

Dev.

\begin{tabular}{|c|c|c|c|c|c|c|c|c|c|}
\hline \multicolumn{10}{|c|}{ Dev. } \\
\hline Govl 255 & 4.11 & 0.943 & Sportl 25 & 3.88 & 1.011 & Sociall & 253 & 3.72 & 1.061 \\
\hline Gov2 253 & 4.08 & 1.057 & Sport2 25 & 3.97 & I.087 & Social2 & 253 & 3.83 & 1.129 \\
\hline Gov3 25 & 3.96 & 1.129 & Sport3 25 & 3.68 & 1.265 & Social3 & 254 & 3.86 & 1.245 \\
\hline Gov4 25 & 3.51 & 1.337 & Sport4 253 & 4.00 & 1.217 & Social4 & 253 & 3.42 & 1.309 \\
\hline Gov5 25 & 4.21 & 1.031 & Sport5 25s & 4.53 & 0.741 & Social5 & 252 & 4.62 & 0.724 \\
\hline Gov6 25 & 3.87 & 1.172 & Sport6 25s & 4.13 & 1.016 & Social6 & 253 & 4.11 & 1.061 \\
\hline Gov7 252 & 3.28 & 1.363 & Sport7 251 & 4.39 & 1.000 & Social7 & 252 & 3.50 & 1.292 \\
\hline Gov8 255 & 4.39 & 0.902 & Sport8 253 & 4.38 & 0.894 & Social8 & 254 & 4.43 & 0.839 \\
\hline Gov9 255 & 4.09 & 1.122 & Sport9 253 & 3.58 & 1.181 & Social9 & 253 & 3.70 & 1.201 \\
\hline Gov10 255 & 4.21 & 1.021 & Sport10 25s & 3.89 & 1.123 & Social10 & 253 & 4.09 & 1.063 \\
\hline Gov11 238 & 3.82 & 1.300 & Sportl1 241 & 3.95 & 1.181 & Social11 & 242 & 4.00 & 1.222 \\
\hline Gov12 253 & 4.04 & 1.029 & Sport12 253 & 3.80 & 1.044 & Social12 & 252 & 3.99 & 1.004 \\
\hline Gov13 253 & 4.40 & 0.789 & Sport13 252 & 4.40 & 0.789 & Social13 & 252 & 4.47 & 0.800 \\
\hline Gov14 249 & 4.35 & 0.968 & Sport14 251 & 4.04 & 1.115 & Sociall4 & 252 & 3.96 & 1.156 \\
\hline Gov15 249 & 2.06 & 1.514 & Sport15 248 & 2.21 & 1.618 & Socialls & 253 & 2.23 & 1.614 \\
\hline Gov16 253 & 4.14 & 1.058 & Sport16 253 & 3.87 & 1.121 & Social16 & 250 & 3.75 & 1.191 \\
\hline Gov17 253 & 3.92 & 1.227 & Sport17 253 & 3.86 & 1.222 & Social17 & 251 & 4.04 & 1.174 \\
\hline Gov18 25 & 4.17 & 0.957 & Sport18 253 & 3.91 & 1.101 & Social18 & 253 & 3.79 & 1.135 \\
\hline Gov19 25 & 4.07 & 0.943 & Sport19 252 & 4.10 & 1.033 & Social19 & 250 & 4.09 & 1.022 \\
\hline Gov20 254 & 4.30 & 1.057 & Sport20 255 & 4.24 & 0.986 & Social20 & 252 & 4.31 & 0.994 \\
\hline
\end{tabular}


A review of this data revealed that all items exhibited an acceptable amount of variance which suggested that the item was able to discriminate between subjects' responses. The largest variances in scores was noted within item number 15 ("an older student") in the government (2.291), sport (2.617) and social (2.604) situations. The lowest amount of variance within an item was found for item number 5 ("a fun person") on the sport ( 0.550$)$ and social situations ( 0.524$)$, respectively.

The item skewness and kurtosis were evaluated across all three survey situations as an indicator of normality within the data distribution. Most items were found to fall within the recommended guidelines of 2.0 for skewness and 4.0 for kurtosis (Tabachnich \& Fidel, 2001). One item (item 5 on the social survey) was found to slightly exceed the recommended limits in skew $(-2.203)$ and kurtosis (5.112). This suggested that the responses on this item tended to be tightly distributed at the high end of possible scores. After careful consideration, the item was retained due to the relatively small magnitude of the violation.

A review of the initial inter-item correlation matrix of all scale items revealed no collinearity between scale items (i.e., no correlations exceeded .6). It was interesting to note that the correlations of identical items across the three situations were similarly low. The highest correlation of a set of identical items across situations was found for item 15 ("an older student") ranging from .482 to .551. Overall, this suggested that items appeared to function differently or discriminate across each situation. 
Survey Order Effects

A $6 \times 9$ MANOVA was completed to investigate the possibility of any order effects between scale and situation despite the researcher's effort to counterbalance survey order. The overall result suggested the presence of an order effect, Wilks $\Lambda=0.719, F(45,835)=1.421, p<.05$, multivariate $\eta^{2}=.064$. Follow-up analyses revealed a single order effect for the Instrumental skill scale within the government situation, $F(5,194)=2.335, p=.044, \eta^{2}=.057$. A review of Tukey tests revealed that there was a significant order effect only between the $2^{\text {nd }}$ and $5^{\text {th }}$ orders of survey presentation. Higher scores were found for the government Instrumental skills scale on the fifth order. Although these analyses identified a significant order effect, the single occurrence of an order effect across the multiple comparisons and the very small effect size for the order effect suggests that it is not likely to represent a systematic order effect but rather seems to be reflective of a random effect.

\section{Principal Components Analysis}

A principal components analysis (PCA) was chosen as a method to gain further exploratory insight into the underlying component structure of the scale. PCA provides an unconstrained analysis of the pattern of variance and covariance among scale items.

The results of the PCA with a varimax rotation suggested that a three factor solution for understanding the adolescent perceptions of peer leadership was viable. This decision was based upon the review of several indices such as Cattell's scree plot procedure (Cattell, 1966), parallel analysis (Horn, 1965) and 
theoretical relevance. The parallel analysis procedure compared the sample produced set of eigenvalues to the average eigenvalue of a random data set of the same sample size. Components are retained if the eigenvalues of this data set exceed the eigenvalue of the random data set (Velicer et al., 2000). Finally, theoretical considerations supported the retention of three components as indicators of an Instrumental, Physical and Personality dimensions when assessing adolescent perceptions of peer leaders.

As a result of the PCA, two scale items were discarded (i.e., "talkative" and "older student") due to complex component loadings as well as low component loadings across all three situations. The PCA results for the government, sport and social situations are shown in Tables 5,6 and 7, respectively. 
Table 5

Government Situation Component Loadings

Item

Component 1 Component 2

Component 3

\begin{tabular}{|c|c|c|c|}
\hline $1 \quad$ Able to solve problems & .754 & .061 & -.113 \\
\hline 2 Cooperative & .607 & .273 & .166 \\
\hline Sensitive to other's feelings & .561 & .201 & .378 \\
\hline $\begin{array}{ll}4 & \text { Involved in many activities }\end{array}$ & .443 & .433 & -.464 \\
\hline $5 \quad$ A fun person & .130 & .684 & .413 \\
\hline $\begin{array}{ll}6 & \text { Popular }\end{array}$ & .139 & .769 & .038 \\
\hline 7 A good athlete & .203 & .697 & -.298 \\
\hline 8 Friendly & .570 & .219 & .511 \\
\hline $9 \quad$ Well organized & .620 & .020 & -.216 \\
\hline 10 Honest & .702 & .105 & .142 \\
\hline 11 Good looking & .141 & .709 & .109 \\
\hline 12 Creative & .539 & .244 & .082 \\
\hline 13 Likeable & .312 & .395 & .613 \\
\hline 14 Intelligent & .694 & .139 & -.127 \\
\hline 15 An older student & .001 & -.030 & .394 \\
\hline 16 A hard worker & .742 & .029 & -.004 \\
\hline 17 Talkative & -.099 & .256 & .286 \\
\hline 18 Able to take control & .511 & .096 & .102 \\
\hline 19 Enthusiastic & .533 & .266 & .323 \\
\hline $20 \quad$ Well dressed & .189 & .649 & .150 \\
\hline
\end{tabular}


Table 6

Sport Situation Component Loadings

Item

Component 1

Component 2

Component 3

\begin{tabular}{|c|c|c|c|c|}
\hline 1 & Able to solve problems & .689 & .168 & -.208 \\
\hline 2 & Cooperative & .601 & .248 & -.223 \\
\hline 3 & Sensitive to other's feelings & .585 & .407 & -.187 \\
\hline 4 & Involved in many activities & .218 & .313 & .662 \\
\hline 5 & A fun person & .215 & .530 & -.066 \\
\hline 6 & Popular & .070 & .791 & .008 \\
\hline 7 & A good athlete & .149 & .574 & .514 \\
\hline 8 & Friendly & .598 & .281 & .048 \\
\hline 9 & Well organized & .677 & .231 & .087 \\
\hline 10 & Honest & .736 & .305 & -.003 \\
\hline 11 & Good looking & .235 & .743 & .023 \\
\hline 12 & Creative & .705 & .037 & .110 \\
\hline 13 & Likeable & .355 & .533 & .122 \\
\hline 14 & Intelligent & .697 & .243 & .136 \\
\hline 15 & An older student & -.001 & .084 & -.569 \\
\hline 16 & A hard worker & .621 & .013 & .369 \\
\hline & Talkative & .014 & .064 & -.058 \\
\hline 18 & Able to take control & .608 & .111 & .152 \\
\hline 19 & Enthusiastic & .586 & .110 & .352 \\
\hline & Well dressed & .188 & .667 & .097 \\
\hline
\end{tabular}


Table 7

Social Situation Component Loadings

Item

Component 1 Component 2 Component 3

\begin{tabular}{|c|c|c|c|c|}
\hline 1 & Able to solve problems & .732 & .230 & -.068 \\
\hline 2 & Cooperative & .714 & .005 & .177 \\
\hline 3 & Sensitive to other's feelings & .694 & -.002 & .360 \\
\hline 4 & Involved in many activities & .120 & .606 & .179 \\
\hline 5 & A fun person & .079 & .178 & .783 \\
\hline 6 & Popular & .108 & .676 & .210 \\
\hline 7 & A good athlete & .050 & .751 & -.009 \\
\hline 8 & Friendly & .543 & -.010 & .595 \\
\hline 9 & Well organized & .681 & .249 & -.009 \\
\hline 10 & Honest & .674 & .020 & .306 \\
\hline 11 & Good looking & .428 & .405 & .114 \\
\hline 12 & Creative & .316 & .454 & .210 \\
\hline 13 & Likeable & .213 & .111 & .768 \\
\hline 14 & Intelligent & .682 & .267 & .091 \\
\hline 15 & An older student & -.077 & .057 & .056 \\
\hline 16 & A hard worker & .635 & .185 & .035 \\
\hline 17 & Talkative & -.162 & .303 & .429 \\
\hline 18 & Able to take control & .468 & .418 & .049 \\
\hline 19 & Enthusiastic & .358 & .371 & .464 \\
\hline 20 & Well dressed & .438 & .424 & .117 \\
\hline
\end{tabular}


Additional analyses investigated the possibility of a 2 or 4 component solution. The results of the 4 component solution were problematic due its failure to converge on the sport situation and the presence of a weak fourth component (i.e, few items loading with weak component loadings $<|0.5|$ ). The possibility of a 2 component solution also was investigated. All analyses converged; however, items loaded disproportionately (2:1 ratio) on component 1 . A review of the practical implications of a two component solution was not theoretically viable. Thus, based upon the empirical data and theoretical considerations a three component solution was retained for further investigation.

\section{Confirmatory Factor Analysis}

The hypothesized factor structure (Table 3) was tested utilizing confirmatory factor analysis (CFA). CFA is procedure that allows for the verification of a predetermined factor structure by determining how close the sample data set resembles the hypothesized model. Several indices of fit were utilized to determine the goodness of fit between the derived sample data set and the conceptualized model. First, chi-square tests were used to determine if the hypothesized model provides a good fit to the data. A small, non-significant chisquare value would indicate that there is there is little difference between the hypothesized model and the data (Gorsuch, 1983, Tabachnich \& Fidel, 2001). The goodness of fit was assessed by the examination of the standardized root mean square residuals (SRMR), including the root mean square residual (RMSEA) and the average absolute standardized residual (AASR). All of these indices refer to the average differences of the pattern of variances and covariances between the 
hypothesized model and the data. Small values (less than .05 ) indicate a goodfitting model. The comparative fit index (CFI) was also assessed. The larger the CFI value, the better the fit of the hypothesized model to the data (Tabachnich \& Fidel, 2001). CFI values of .90 or better generally indicate good model fit to the data.

CFA was initially completed utilizing all scale items for the entire sample across each of the three situations. These analyses resulted in significant chisquare tests for the government, sport and social situation, $\chi^{2}(167, N=255)=$ $453.299, \mathrm{p}<.001, \chi^{2}(167, \mathrm{~N}=255)=429.579, \mathrm{p}<.001, \chi^{2}(167, \mathrm{~N}=255)=$ 467.351, $\mathrm{p}<.001$ ), respectively. Additionally, the CFI did not exceed the .90 guideline for good fit $(\mathrm{CFI}$ government $=.794, \mathrm{CFI}$ sport $=.800, \mathrm{CFI}$ social $=$ .793) (Tabachnich \& Fidel, 2001). A review of the model residuals revealed RMSEA values greater than .05 across all three situations (government $=.089$, sport $=.085$, social $=.09$ ). AASR values were also slightly above the accepted range of less than .05 (government $=.060$, sport $=.0506$, social $=.0579$ ). Based upon the CFA the hypothesized factor structure was not found to be a good fit with the derived sample model.

The results of the Wald test suggested that the elimination of the 2 items identified as problematic by the PCA's ("talkative" and "an older student") would significantly improve model fit. A review of the LaGrange Multiplier Test (LMT) suggested the presence of three complex scale items ("involved in many activities", "a fun person", "likeable" and "friendly"). Complex items refer to a 
scale item that loads on more than one factor and creates ambiguity within analyses.

\section{Exploratory Analyses}

Further analyses were completed for exploratory purposes to refine the Adolescent Perception of Peer Leader Effectiveness (APPLE) scale items. Information from both the initial PCA and CFA suggested that several of the original scale items were poor items. Based upon these analyses, six original items were discarded (i.e., "involved in many activities", "a fun person", "likeable", "friendly", "an older student" and "talkative").

A follow-up CFA was completed utilizing the revised version of the scale (Table 8). The CFA results revealed an overall improvement in fit across all three situations. Although the chi-square indices were significant [government: $\chi^{2}(74$, $\mathrm{N}=255)=123.815, \mathrm{p}<.001 ;$ sport: $\chi^{2}(74, \mathrm{~N}=255)=169.553, \mathrm{p}<.001$; social: $\chi^{2}(74$, $\mathrm{N}=255)=156.667, \mathrm{p}<.001)]$, there was an improvement in the CFI across all situations $($ government $=.944$, sport $=.914$, social $=.917)$. Additional indices of fit also demonstrated an overall improvement in RMSEA across situations (government $=.055$, sport $=.075$, social $=.070)$ and AASR $($ government $=.0354$, sport $=.0393$, social $=.0445)$. Overall, these findings suggested that the revised Adolescent Perception of Peer Leader Effectiveness scale was a better fit to the derived sample. 
Table 8

Revised Scale Factor Loading Structure- Government Situation

\begin{tabular}{|c|c|c|c|c|c|}
\hline Instrumental & Loading & Physical & Loading & Personal & Loading \\
\hline 1. Able to solve problems & .73 & 6. Popular & .70 & 2. Cooperative & .68 \\
\hline 9. Well organized & .53 & $\begin{array}{l}\text { 7. A good } \\
\text { athlete }\end{array}$ & .51 & 3. Sensitive to other & $\begin{array}{ll}\text { eers } & .61\end{array}$ \\
\hline 12. Creative & .55 & $\begin{array}{l}\text { 11. Good } \\
\text { looking }\end{array}$ & .74 & 10. Honest & .70 \\
\hline 14. Intelligent & .66 & $\begin{array}{l}\text { 20. Well- } \\
\text { dressed }\end{array}$ & .69 & 19. Enthusiastic & .61 \\
\hline 16. Hard worker & .70 & & & & \\
\hline 18. Able to take control & .49 & & & & \\
\hline
\end{tabular}

Table 9

Revised Scale Factor Loading Structure- Sport Situation

Instrumental Loading Physical Loading Personal

Loading

\begin{tabular}{lccclc}
\hline 1. Able to solve problems & .66 & 6. Popular & .66 & 2. Cooperative & .60 \\
\hline 9. Well organized & .73 & 7. A good athlete & .53 & 3. Sensitive to others & .63 \\
\hline 12. Creative & .62 & 11. Good looking & .81 & 10. Honest & .81 \\
\hline 14. Intelligent & .71 & 20. Well dressed & .68 & 19. Enthusiastic & .54 \\
\hline 16. Hard worker & .57 & & & & \\
\hline 18. Able to take control & .56 & & & & \\
\hline
\end{tabular}


Table 10

Revised Scale Factor Loading Structure- Social Situation

Instrumental Loading Physical Loading Personal

Loading

\begin{tabular}{llllll}
\hline 1. Able to solve problems & .72 & 6 . Popular & .66 & 2 . Cooperative & .64
\end{tabular}

9. Well organized $\quad .66 \quad 7$. A good athlete $\quad .33 \quad 3$. Sensitive to others $\quad .75$

$\begin{array}{llllll}\text { 12. Creative } & .47 & 11 \text {. Good looking } & .73 & 10 . \text { Honest } & .69\end{array}$

$\begin{array}{llllll}\text { 14. Intelligent } & .72 & 20 \text {. Well dressed } & .76 & \text { 19. Enthusiastic } & .53\end{array}$

16. Hard worker $\quad .62$

18. Able to take control $\quad .58$

A review of correlations between scales within and across situations revealed relatively low correlations between scales across situations (Table 11).

Interestingly, the highest correlations were obtained between the Instrumental

Skills factor and the Personal Attribute factor within each situation. 
Table 11

Revised Scale Correlations

Table 11

Revised Scale Correlations

Instrumental Loading Physical Loading Personal Loading

\begin{tabular}{lccccccccc}
\hline & Gov. & Gov. & Gov. & Sport & Sport & Sport & Social & Social & Social \\
& Inst. & Phys. & Pers. & Inst. & Phys. & Pers. & Inst. & Phys. & Pers. \\
\hline Gov. Inst. & 1.00 & & & & & & & & \\
\hline Gov. Phys. & 0.34 & I.00 & & & & & & & \\
\hline Gov. Pers. & 0.62 & 0.43 & 1.00 & & & & & \\
\hline Sport Instr. & 0.36 & 0.28 & 0.41 & 1.00 & & & & \\
\hline Sport Phys. & 0.26 & 0.32 & 0.40 & 0.44 & 1.00 & & & \\
\hline Sport Pers. & 0.30 & 0.23 & 0.45 & 0.68 & 0.51 & 1.00 & & \\
\hline Social Instr. & 0.25 & 0.36 & 0.34 & 0.30 & 0.25 & 0.33 & 1.00 & & \\
\hline Social Phys. & 0.15 & 0.32 & 0.33 & 0.17 & 0.33 & 0.31 & 0.47 & 1.00 & \\
\hline Social Pers. & 0.15 & 0.25 & 0.35 & 0.15 & 0.23 & 0.29 & 0.69 & 0.42 & 1.00 \\
\hline
\end{tabular}

Internal scale consistency was assessed for the three scales across all scenarios (i.e., government, sport, social) by calculating Cronbach's alpha (see Table 12). All scores except the Physical Scale in the social situation obtained adequate internal consistency value of .70 or higher (DeVellis, 1991). 
Table 12

Scale Means, Standard Deviations and Coefficient Alphas

\begin{tabular}{lrrrrr}
\multicolumn{1}{c}{ Scales } & \multicolumn{2}{c}{$\begin{array}{c}\text { Number } \\
\text { of Items }\end{array}$} & $\begin{array}{c}\text { Alpha } \\
\text { Alpha }\end{array}$ & Mean & $\begin{array}{c}\text { Standard } \\
\text { Deviation }\end{array}$ \\
\hline Government- & 6 & .78 & 24.91 & 4.22 \\
Instrumental & & & & & \\
& & & & & \\
\hline Government- & 4 & .76 & 15.30 & 3.68
\end{tabular}

Physical

\begin{tabular}{lllll}
\hline Government- & 4 & .73 & 16.37 & 3.15
\end{tabular}

Personal

\begin{tabular}{lcccc}
\hline Sport- Instrumental & 6 & .80 & 23.26 & 4.58 \\
\hline Sport- Physical & 4 & .75 & 16.82 & 3.14 \\
\hline Sport- Personal & 4 & .75 & 15.63 & 3.43 \\
\hline Social- Instrumental & 6 & .79 & 22.89 & 4.76 \\
\hline Social- Physical & 4 & .69 & 15.96 & 3.26 \\
\hline Social- Personal & 4 & .74 & 15.87 & 3.37 \\
\hline
\end{tabular}

\section{Alternative Model Comparisons}

Four models (null, 1 factor, 3 factor uncorrelated, 3 factor correlated) were constructed and tested to explore plausible alternative factor configurations for the Adolescent Perception of Peer Leader Effectiveness scale (APPLE) across all three situations. The Null model posits that there is no relationship between scale items. This model was not considered to be a viable model, however, it is used for a 
baseline comparison for which the remaining three models are compared. The 1Factor model is the most basic model and suggests that there is only one underlying factor influencing adolescent perceptions of peer leader effectiveness. An uncorrelated three factor model hypothesizes that there are three separate independent factors that can explain adolescent perceptions of peer leaders. Finally, the correlated three factor model would suggest that the three factors utilized to explain adolescent perceptions are related constructs and may provide evidence that there is a higher order construct for adolescent perceptions of peer leaders.

The competing models of adolescent perceptions of peer leaders were evaluated and compared across all three situations (see Tables 13, 14 and 15). Table 13

Comparison of Measurement Models for the Government Situation

\begin{tabular}{lcccccc} 
Model & $\chi^{2}$ & df & AASR & RMSEA & CFI & P \\
\hline Null Model & 984.558 & 91 & 0.2562 & 0.209 & 0.000 & $\mathrm{p}<.001$ \\
\hline 1 Factor & 272.171 & 77 & 0.0552 & 0.106 & 0.782 & $\mathrm{p}<.001$ \\
Model & & & & & & \\
\hline 3 Factor & 295.210 & 77 & 0.1846 & 0.112 & 0.756 & $\mathrm{p}<.001$ \\
uncorrelated & & & & & & \\
\hline 3 Factor- & 123.815 & 74 & 0.0354 & 0.055 & 0.944 & $\mathrm{p}<.001$ \\
correlated & & & & & & \\
\hline
\end{tabular}


Table 14

Comparison of Measurement Models for the Sport Situation

\begin{tabular}{lcccccc} 
Model & $\chi^{2}$ & $\mathrm{df}$ & AASR & RMSEA & CFI & $\mathrm{P}$ \\
\hline Null Model & 1026.002 & 91 & 0.2928 & 0.232 & 0.000 & $\mathrm{p}<.001$ \\
\hline 1 Factor & 297.421 & 77 & 0.0553 & 0.112 & 0.803 & $\mathrm{p}<.001$ \\
Model & & & & & & \\
\hline 3 Factor & 426.388 & 77 & 0.1942 & 0.141 & 0.687 & $\mathrm{p}<.001$ \\
uncorrelated & & & & & & \\
\hline 3 Factor- & 169.553 & 74 & 0.0393 & 0.075 & 0.914 & $\mathrm{p}<.001$ \\
correlated & & & & & & \\
\hline
\end{tabular}

Table 15

Comparison of Measurement Models for the Social Situation

\begin{tabular}{lcccccc} 
Model & $\chi^{2}$ & df & AASR & RMSEA & CFI & $\mathrm{P}$ \\
\hline Null Model & 1086.232 & 91 & 0.3553 & 0.219 & 0.000 & $\mathrm{p}<.001$ \\
\hline 1 Factor & 252.355 & 77 & 0.0516 & 0.100 & 0.824 & $\mathrm{p}<.001$ \\
Model & & & & & & \\
\hline 3 Factor & 358.828 & 77 & 0.2382 & 0.128 & 0.716 & $\mathrm{p}<.001$ \\
uncorrelated & & & & & & \\
\hline 3 Factor- & 156.667 & 74 & 0.0445 & 0.070 & 0.917 & $\mathrm{p}<.001$ \\
correlated & & & & & & \\
\hline
\end{tabular}




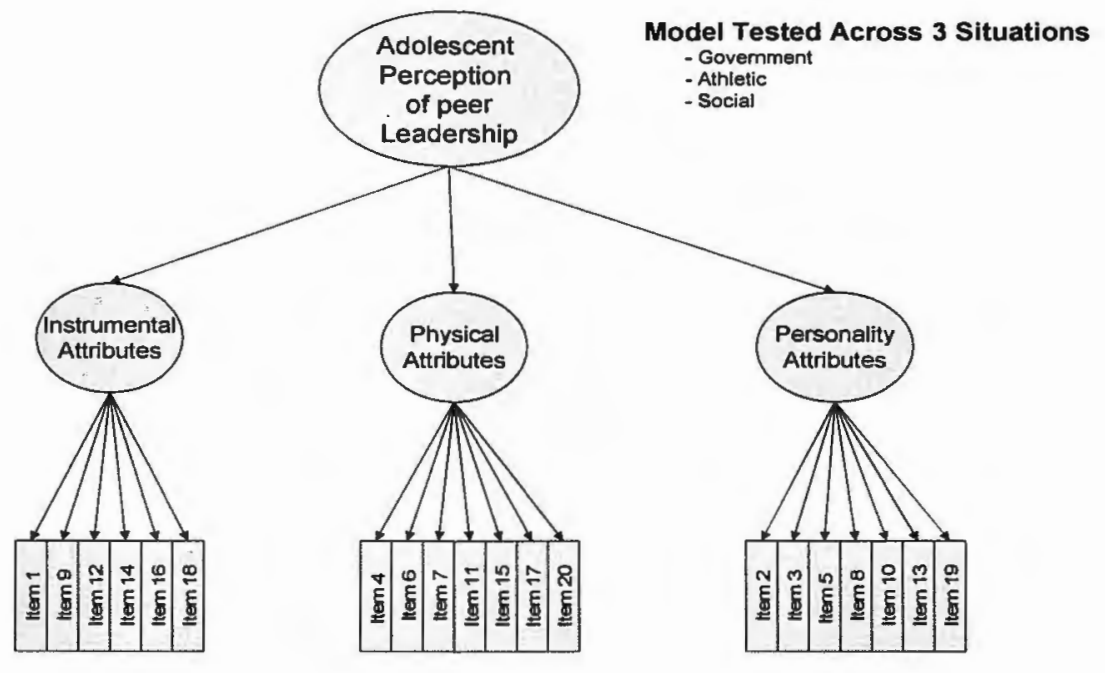

Figure 1: Conceptual Model

Across all three situations, the three factor correlated model was found to be the best fitting model based upon the CFI and RMSEA indices (see Figure 1). The CFI indices of the three-factor correlated model across all three situations were greater than the .90 criteria for adequate fit (Tabachnich \& Fidel, 2001).

Although the RMSEA values were greater than the recommended value of .05 , the lowest RMSEA values were obtained by the three-factor correlated model across all three situations. Finally, the results of the $\chi^{2}$ difference test suggested that across all three situations, the 3-factor correlated model provided a significantly better fit to the data than both the 1 factor model (government: $\chi^{2}$ diff $=148.356, \mathrm{df}$ $=3, p<.001$, sport: $\chi_{\text {diff }}^{2}=127.868, d f=3, p<.001$, social: $\chi_{\text {diff }}^{2}=95.688, d f=3$, $\mathrm{p}<.001$ ) and the 3 factor uncorrelated model (government: $\chi_{\text {diff }}^{2}=171.395, \mathrm{df}=$ $3, p<.001$, sport: $\chi_{\text {diff }}^{2}=256.835, \mathrm{df}=3, \mathrm{p}<.001$, social: $\chi_{\text {diff }}^{2}=202.161, \mathrm{df}=3$, $\mathrm{p}<.001$ ). These finding suggested that the 3 factor correlated model was the best 
fit to the data. The correlations between factors across the three situations are provided in Table 16.

Table 16

Maximum-likelihood Correlations between factors across situations

Situation

Instrumental \&

Instrumental \&

Physical \&

Physical

Personality

Personality

\begin{tabular}{llll}
\hline Government & .42 & .86 & .56 \\
\hline Sport & .54 & .94 & .65 \\
\hline Social & .61 & .87 & .59 \\
\hline
\end{tabular}

Between Group Analyses

A single $2 \times 2 \times 3$ MANOVA was run to determine if there were age and gender effects in adolescent perceptions of leadership. The overall results of the MANOVA revealed no significant age differences across scales (Wilks' $\Lambda=.995$, $\mathrm{F}(3,194)=0.347, \mathrm{p}=.792)$ and no significant interaction between age and gender (Wilks' $\Lambda=.971, \mathrm{~F}(3,194)=1.945, \mathrm{p}=.124)$. However, there was a significant difference noted between genders (Wilks' $\Lambda=.924, \mathrm{~F}(3,194)=5.344, \mathrm{p}<.001$, multivariate $\eta^{2}=.076$ ) with females rating peer leaders higher than males.

Follow-up ANOVA tests confirm this tendency for female students to rate peers higher was consistent across all three scales: Instrumental scale $\mathrm{F}(1,196)=$ $4.973, p=.027, \eta^{2}=.0275$, Physical scale $F(1,196)=7.223, p=.008, \eta^{2}=.036$ and Personality scale $\mathrm{F}(1,196)=14.986, \mathrm{p}<.001, \eta^{2}=.071$. 
Separate $2 \times 2 \times 3$ MANOVAs were completed to further investigate age and gender differences within each of the three situations (government, sport, social). The results of the government situation MANOVA revealed significant gender differences (Wilks' $\Lambda=.932, \mathrm{~F}(3,219)=5.304, \mathrm{p}<.05$, multivariate $\eta^{2}=.068$ ). Follow-up analyses revealed that females significantly rated peer leaders higher on the Personality scale, $\mathrm{F}(1,221)=13.41, \mathrm{p}<.001, \eta^{2}=.057$. In the sport situation the overall MANOVA also revealed significant differences between genders $\left(\right.$ Wilks' $\Lambda=.926, \mathrm{~F}(3,223)=5.976, \mathrm{p}<.001$, multivariate $\left.\eta^{2}=, 074\right)$. Interestingly, follow-up analyses indicated that females rated peer leaders significantly higher than males on the Physical Attribute scale, $F(1,225)=17.09$, $p<.001, \eta^{2}=.071$. The MANOVA for the social situation also revealed significant gender effects (Wilks' $\Lambda=.963, \mathrm{~F}(3,223)=2.846, \mathrm{p}<.05$, multivariate $\eta^{2}=.037$ ). In the social situation, follow-up ANOVA revealed significant gender differences in rating on the Instrumental scale, $F(1,225)=$ $4.631, \mathrm{p}<.05, \eta^{2}=.02$, and the Personality scale, $\mathrm{F}(1,225)=8.422, \mathrm{p}<.05, \eta^{2}=$ $.05, \eta^{2}=.036$. 


\section{Discussion}

Overall, the results of this investigation found some preliminary support for the existence of a three-factor measurement model for adolescent perceptions of peer leaders. Although the initial confirmatory factor analyses revealed that the proposed underlying factor structure of the Adolescent Perceptions of Peer Leader Effectiveness (APPLE) was not strongly supported by the available data, exploratory post-hoc modifications significantly improved the model fit without violating the context of the original model. A second finding revealed no significant age differences between high school and middle school students in their measured perceptions of peer leaders.

\section{Measurement Issues}

Adolescence is a time of great physical, emotional, cognitive and social change. As part of this change process, adolescents shape their perceptions of themselves and others around them. Little is known about how adolescents conceptualize leadership. This is partly due to the overall sparse nature of empirical research on adolescent leadership and partly due to the lack of published measures of adolescent perceptions on leadership. In the process of developing the APPLE scale, this research project focused on understanding and identifying the dimensions that underlie adolescent perceptions of peer leaders.

Although the preliminary investigation of the underlying factor structure of this scale revealed discrepancies between the hypothesized model and the current sample, these analyses provided valuable insight for the revision of this scale. The initial analyses of the adolescent perceptions of peer leader scale suggested the 
presence of six poorly performing scale items. Two of these items (e.g., "talkative" and "an older student") were deleted due to their failure to load significantly on any factor and suggested that these items were not consistently able to contribute to any of the hypothesized underlying constructs. Another four items were deleted from the scale due to the complex nature of their relationship to the three hypothesized factors (i.e., items loaded on more than 1 factor). These post hoc revisions to the scale resulted in a 14 item questionnaire that not only provided a statistical good fit to the data but also maintained the structure and theoretical integrity of the original hypothesized model.

An analysis of the revised 14 item scale revealed that the three factor structure (instrumental, physical, personality) was maintained across all three scenarios (government, sport, social). It was noted that the factor structure was most strongly supported within the government leadership scenario. One possible explanation may lie in the fact that the government scenario is the most taskspecific situation and that the strongest factor across all settings was the factor that measured specific instrumental behaviors. In contrast, the social and sport scenarios required multiple skill sets (i.e., instrumental abilities, personality skills and physical attributes). Thus, the measurement of these additional skills may have compromised the model fit due to the weaker nature of the factors structure designed to measure personality and physical attributes. Overall, these findings suggested that there is evidence that the general factor structure was consistent across situations. 
Social Awareness Development in Adolescent Perceptions of Leadership

Additional analyses revealed that there were no significant age differences noted between the high school and middle school students. However, a review of group means revealed that middle school students on average endorsed items on the all three scales at a higher rate than high school students. In addition, higher variability of item responses was noted for the middle school sample. These findings suggest that a wider range of variability in the perception of effective peer leaders within the middle school sample than the high school sample. Additional research would be needed to determine if these differences are suggestive of a developmental difference or a unique characteristic of this particular sample. At this time, there appears to be very limited support for the role of social awareness in the development of the perception of peer leaders.

\section{Gender Differences}

Interestingly, there was a significant gender difference in the way students rated their perception of an effective peer leaders. Although both groups tended to rate perceived leaders highly, both younger and older female students, on average, rated their perception of effective leaders across all three scenarios significantly higher than their male counterparts. This finding seems to suggest that female students tended to support their perceptions of effective leadership with a stronger endorsement of peer leaders' abilities than male students. Furthermore, these differences were not consistent across scales or situations. For example, in the government situation females rated peer leaders significantly higher on the Personality scale. In contrast, females rated peer leaders significantly higher in the 
sport situation on the Physical scale. Lastly, females rated Instrumental and Personality scales higher in the social situation. These finding suggest that females may endorse scale items higher if the item is perceived as central to successful leadership within a particular situation. Further research is needed to determine if these differences are due to true differences in the perception of effective peer leader or due to an overall tendency for females to respond higher to Likert scale items.

\section{Limitations and Future Research}

There are several limitations to this study that are related to sampling issues. First, the demographic composition of the sample did not represent a diverse group of adolescents across several variables (i.e., age, ethnicity, socio-economic status). Next, there was a large discrepancy between the middle school and high school sample sizes. Thus, analyses were more heavily weighted by the middle school sample. Additionally, the relatively small high school sample made separate PCA and CFA for the high school sample statistically problematic. Finally, sample size was not large enough to conduct a split-half cross-validation of the model, thus true confirmatory analyses were not possible.

Another limitation of this study concerns the post hoc refinement of this scale. Due to these follow-up analyses, two factors (Personality skills, Physical attributes) have been reduced to four items. Although the paring down of the original scale was justified statistically and theoretically and maintained adequate coefficient alphas, this resulted in a weakening of the Personality and Physical attribute scales. 
Finally, this study is limited due to its cross-sectional design. These results are reflective of a single point in time and limited conclusions can be made about the consistency over time for the factor structure of this measurement of adolescent perception. Although the conclusions are somewhat limited, this project was able to provide some preliminary support for the hypothesized 3-factor structure by demonstrating that the same 3 -factor structure was consistent across three situations.

This study has several implications for future research. First, there is the need to verify the post hoc revisions made to this scale on an independent sample. Once independent verification of the measurement model has been established, the next step would be to administer the scale to another sample for replication of the model. Once the measurement scale has been verified and replicated, future research can address more specific issues raised within this project regarding the role of gender, age and social awareness in the development of adolescent perceptions of effective peer leadership. 


\section{Appendices}

\section{Appendix A}

\section{Consent Form}

To: $\quad$ Parents and Students

From: C. Stephan

Date:

A survey of young people's understanding of social relations is being conducted in the Chariho high school. Students from the seventh and twelfth grade have been selected to participate. This project has been authorized as part of the education and research program at the University of Rhode Island under the supervision of Dr. Janet Kulberg, Dr. Jacqueline Wilk, and Dr. Joseph Rossi.

Students will be asked to complete three surveys concerning the characteristics they value in three peer leadership situations. Each survey will take approximately five to ten minutes to complete. The entire project will be completed during one classroom period. Participation is voluntary and students are free to refuse to answer any specific item or questions. Students will be told not to include any identifying information and responses will be coded by age and sex. Every possible precaution will be taken to insure student confidentiality.

The investigator and the school administrators do not foresee any harm or risk to students as a result of their participation. If there are any concerns or questions, please call Ms. Stephan at 783-1211. Otherwise, please return this form to the school as soon as possible.

Thank you for your cooperation.

My son/daughter,

may participate in this research project.

may not participate in this research project.

Date

Signature of parent or guardian 


\section{Appendix B}

\section{Directions}

"You and other students in the school have been selected to be part of a research project about what students think about different types of leaders. You will be handed a three-page survey with some questions on it. This is not a test. There are no right or wrong answers. The investigators would like you answer this survey the way you really think. This is a voluntary project, if there are some questions or items which you are not comfortable answering, you may choose not to respond to those particular items. When you have completed the survey, please turn the sheet over on your desk. These forms will be collected and put in a sealed envelope. No one but the people working on this project from the University of Rhode Island will see your paper. If you have any questions just raise your hand. (Hand out forms)

Now in the top right hand corner of the page, please write down the month and year that you were born. Do not write your name or any other identifying information on your paper. Remember if you have any questions raise your hand. You may begin." 


\section{Appendix C}

\section{Social Committee Scale}

I am a ... (please mark one) Female Male

1. Your school is planning a big party. Write the initials of a person your own age who you would like to choose to be in charge of this party:

Please mark one:
() Female
() Male

2. Rate the person you cliose above on the following list of characteristics:

The person you choose is ...

$\begin{array}{lllll}\begin{array}{l}\text { Not true } \\ \text { of this }\end{array} & \begin{array}{l}\text { A little } \\ \text { true of }\end{array} & \begin{array}{l}\text { Somewhat } \\ \text { true of }\end{array} & \begin{array}{l}\text { Usually } \\ \text { true of }\end{array} & \begin{array}{l}\text { Very true } \\ \text { of this }\end{array} \\ \text { person } & \text { person } & \text { this person } & \text { this person } & \text { person }\end{array}$

1. able to solve problems

2

2. cooperative

3. sensitive to other's feelings 1

4. involved in many activities

5. a fun person

6. popular

7. a good athlete

8. friendly

9. well organized

10. honest

11. good looking

12. creative

13 likeable

14. intelligent

15. an older student

16. a hard worker

17. talkative

18. able to take control of a situation

19. enthusiastic

20. well dressed this person

3. Are there any other characteristics that describe this person?

\begin{tabular}{|c|c|c|}
\hline 3 & 4 & 5 \\
\hline 3 & 4 & 5 \\
\hline 3 & 4 & 5 \\
\hline 3 & 4 & 5 \\
\hline 3 & 4 & 5 \\
\hline 3 & 4 & 5 \\
\hline 3 & 4 & 5 \\
\hline 3 & 4 & 5 \\
\hline 3 & 4 & 5 \\
\hline 3 & 4 & 5 \\
\hline 3 & 4 & 5 \\
\hline 3 & 4 & 5 \\
\hline 3 & 4 & 5 \\
\hline 3 & 4 & 5 \\
\hline 3 & 4 & 5 \\
\hline 3 & 4 & 5 \\
\hline 3 & 4 & 5 \\
\hline 3 & 4 & 5 \\
\hline 3 & 4 & 5 \\
\hline 3 & 4 & 5 \\
\hline
\end{tabular}

4. What characteristics were most important?
b.
c.

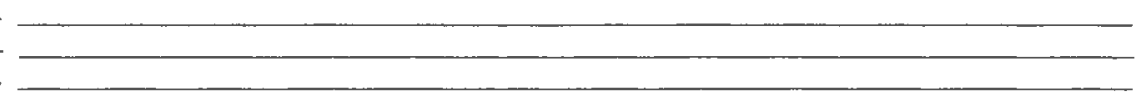




\section{Appendix D}

\section{Student Government Scale}

I am a ... (please mark one) Female Male

1. Write the initials of a person your own age who you would like to choose to be a leader in student government (i.e., class president, student council)::

Please mark one:

( ) Female () Male

2. Rate the person you chose above on the following list of characteristics:

The person you choose is ...

\begin{tabular}{|c|c|c|c|}
\hline $\begin{array}{l}\text { Not true } \\
\text { of this } \\
\text { person }\end{array}$ & $\begin{array}{l}\text { A little } \\
\text { true of } \\
\text { person }\end{array}$ & $\begin{array}{l}\text { Somewhat } \\
\text { true of } \\
\text { this person }\end{array}$ & $\begin{array}{l}\text { Usually } \\
\text { true of } \\
\text { this person }\end{array}$ \\
\hline
\end{tabular}

1. able to solve problems

12

3

2. cooperative

1

3. sensitive to other's feelings

\section{2}

3

4. involved in many activities

\section{2}

3

5. a fun person

2

3

6. popular

7. a good athlete

8. friendly

9. well organized

10. honest

11. good looking

12. creative

13 likeable

14. intelligent

15. an older student

16. a hard worker

17. talkative

18. able to take control of a situation

23

23

23

23

23

3

3

45

9. enthusiastic

20. well dressed

1
1

2

2

3

4

4

4

4

4

45

3. Are there any other characteristics that describe this person?

4. What characteristics were most important?
a.
b.
c. 


\section{Appendix E}

\section{Athletic Team Scale}

I am a ... (plcase mark one) Female Male

1. Write the initials of a person your own age who you would like to choose as a leader on a team sport (i.e., team captain):

Please mark one:
() Female
() Male

2. Rate the person you chose above on the following list of characteristics:

The person you choose is ...

$\begin{array}{lllll}\begin{array}{l}\text { Not true } \\ \text { of this }\end{array} & \begin{array}{l}\text { A little } \\ \text { true of }\end{array} & \begin{array}{l}\text { Somewhat } \\ \text { true of }\end{array} & \begin{array}{l}\text { Usually } \\ \text { true of }\end{array} & \begin{array}{l}\text { Very true } \\ \text { of this }\end{array} \\ \text { person } & \text { person } & \text { this person } & \text { this person } & \text { person }\end{array}$

1. able to solve problems

12

3

2. cooperative

\section{2}

3

5

3. sensitive to other's feelings

2

3

4. involved in many activities

\section{2}

3

5. a fun person

$$
2
$$

3

6. popular

7. a good athlete

8. friendly

9. well organized

10. honest

11. good looking

12. creative

13 likeable

14. intelligent

15. an older student

2

3

4

4

5

5

16. a hard worker

2

3

4

4

5

17. talkative

\section{2}

3

4

4

5

18. able to take control of a situation

$$
2
$$

3

3

4

4

45

45

19. enthusiastic

23

4

5

20. well dressed

\section{2}

3

4

5

5

5

23

4

4

45

23

45

23

45

23

4

5

3. Are there any other characteristics that describe this person?

4. What characteristics were most important?

a.

b.

c. 


\section{Bibliography}

Asher, S. R, Markell, R. A. \& Hymel, S. (1981). Identifying children at risk in Peer relations: A critique of the rate-of-interaction approach to assessment. Child Development, 52 (4), 1239- 1245.

Bean, S. M., \& Karnes, F. A. (2001). Developing leadership potential of gifted students. In F. A. Karnes \& S. M. Bean (Eds.), Methods and materials for teaching the gifted (pp. 559-586). Waco, TX: Prufrock Press.

Blank, T. O. (1986). What high school leaders think of leadership. High School Journal. 69, 207-213.

Breckenridge, M. E., \& Vincent, E. L. (1965). Child development. Philadelphia: Saunders.

Catell, R. B. (1966). The scree test for number of factors. Multivariate Behavioral Research, 1, 245-276

Davis, T. R., \& Luthans, F. (1984). Defining and researching leadership as a behavioral construct: An idiographic approach. Journal of Applied Behavioral Sciences. 20, 237-251.

DeVellis, R. F. (2003). Scale development: Theory and applications $\left(2^{\text {nd }}\right.$ Ed.). Newbury Park: Sage Publications.

Dobosz, R. P., \& Beaty, L. A. (1999). The relationship between athletic participation and high school students' leadership ability. Adolescence, 34 (133), 215-220.

Fiedler, F. E. (1978). Recent developments in research on the contingency model. In L. Berkowitz (ed.). Group Processes. New York: Academic Press. 
Fiedler, F. E. (1967). A theory of leadership effectiveness. New York: McGraw Hill.

Fleming, E. G. (1935). A factor analysis of the personality of high school leaders. Journal of Applied Psychology, 42, 267-284.

Fu, V. R., Canaday, H., \& Fu, D. T. (1982). Creativity and leadership in preschoolers. The Journal of Genetic Psychology, 141, 291-292.

Gorsuch, R. L. (1983). Factor analysis. (2 ${ }^{\text {nd }}$ ed.). Hillsdale, NJ: Lawrence Erlbaum Associates.

Gouldner, A. (1950). Studies in leadership. New York: Harper \& Row. Guadagnoli, E., \& Velicer, W. F. (1988). Relation of sample size to the stability of component patterns. Psychological Bulletin, 103(2), 265- 275.

Hannah, M. E. (1979). High school situational and personal components. Journal of Psychology, 103, 163-168.

Hook, S. (1955). The hero in history. Boston: Beacon Press.

Horn, J. (1965). A rationale and test for the number of factors in factor analysis. Psychometrika, 30, 179-185.

Klonsky, B. G. (1983). The socialization and development of leadership. Genetic Psychology Monographs, 108, 98- 135.

Lautenschlager, G. J. (1989). A comparison of alternatives to conducting Monte Carlo analyses for determining parallel analysis criteria. Multivariate Behavioral Research, 24(3), 365- 395. 
McCullough, P. M., Ashbridge, D. \& Pegg, R. (1994). The effect of self-esteem, family structure, locus of control and career goals on adolescent leadership behavior. Adolescence, 29 (115), 605- 611.

Morris, C. G., \& Hackman, J. R. (1969). Behavioral correlations of perceived leadership. Journal of Personality and Social Psychology, 13, 350-361.

Nutting, R. L. (1976). Some characteristics of leaderships. School and Society, $18,387-390$.

Oakland, T., Falkenberg, B. A., \& Oakland, C. (1996). Assessment of leadership in children, youth and adults. Gifted Child Quarterly, 40 (3), 138- 146

Oppenheimer, L., \& Thijssen, F. (1983). Children's thinking about friendships and its relation to popularity. The Journal of Psychology, 114, 69-78.

Peery, J. C. (1979). Popular, amiable, isolated, rejected: A reconceptualization of sociometric status in preschool children. Child Development, 50, 1231-1234.

Scales, P. C., Benson, P. L., \& Leffert, N. (2000). Contribution of developmental assets to the prediction of thriving among adolescents. Applied Developmental Science, 4(1), 27-46.

Schneider, B., Ehrhart, K. H. \& Ehrhart, M. G. (2002). Understanding high school leaders II. Peer nominations of leaders and their correlates. The Leadership Quarterly, 13, 275- 299.

Selman, R. L. (2003). The promotion of social awareness: Powerful lessons from the partnership of developmental theory and classroom practice. New York: Russell Sage Foundation. 
Selman, R. L. (1980). The growth of interpersonal understanding:

Developmental and clinical analyses. New York: Academic Press.

Selman, R. L. (1976). Toward a structural analysis of developing interpersonal relations concepts: Research with normals and disturbed adolescent boys. In A. Pick (Ed.), Tenth annual Minnesota symposium on child psychology. (pp. 156-200). Minneapolis: University of Minnesota Press.

Simonton, D. F. (1979). Multiple discovery and invention: Zeitgeist, genius or chance? Journal of Personality and Social Psychology, 37, 1603-1616.

Suedfeld, P., \& Rank, A. D. (1976). Revolutionary leaders: Long-term success as a function of changes in conceptual complexity. Journal of Personality and Social Psychology, 34,169-178.

Tabachnick, B. G., \& Fidell, L. S. (2001). Using multivariate statistics. $\left(4^{\text {th }} E d\right.$.). Boston: Allyn \& Beacon.

Velicer, W. F. (1976). Determining the number of components from the matrix of partial correlations. Psychometrika, 41(3), 149-159.

Velicer, W., Eaton, C., \& Fava, J. (2000). Construct explication through factor of component analysis: A review and evaluation of alternative procedures for determining the number of factors or components. In R. Griffin, \& E. Helmes (Eds.), Problems and Solutions in Human Assessment: A Festschrift to Douglas Jackson at Seventy. Boston: Kluwer Academic Publishers.

Wood, F. A. (1913). The influence of monarchs. New York: Macmillan. 
Zakin, D. F. (1983). Physical attractiveness, sociability, athletic ability and children's preferences for their peers. The Journal of Psychology, 115, 117112. 